\title{
Erratum to: Competitive price-matching guarantees under imperfect store availability
}

\author{
Arcan Nalca • Tamer Boyaci • Saibal Ray
}

Published online: 19 March 2010

(C) Springer Science+Business Media, LLC 2010

\section{Erratum to: Quant Mark Econ \\ DOI 10.1007/s11129-010-9080-1}

The Acknowledgements section in the original version of this article unfortunately was incomplete. The detailed and complete information is given below.

Acknowledgements We thank Prof. Adolfo De Motta for helpful comments on earlier versions of the manuscript. We also thank the co-editor Prof. Rajiv Lal for his guidance through the review process. The usual disclaimer applies. The research was partially supported by grants from the Natural Sciences and Engineering Research Council (NSERC) of Canada for Tamer Boyaci and Saibal Ray.

The online version of the original article can be found at http://dx.doi.org/10.1007/s11129-010-9080-1.

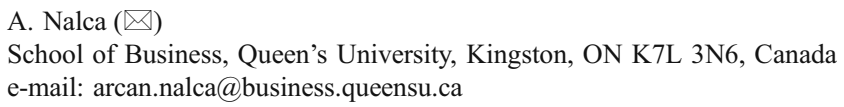

S. Ray

e-mail: saibal.ray@mcgill.ca 